\title{
PENGARUH VARIASI TEMPERATUR TUANG TERHADAP KETANGGUHAN IMPAK DAN STRUKTUR MIKRO PADA PENGECORAN ALUMINIUM
}

\author{
Mohammad Tofa Wijaya \\ Program Studi Teknik Mesin Fakultas Teknologi Industri \\ Universitas Surakarta \\ Email: topa.topenk@gamil.com \\ Zubaidi \\ Program Studi Teknik Mesin Fakultas Teknologi Industri \\ Universitas Surakarta \\ Email: joe@pancanakagroup.com \\ Wijoyo \\ Program Studi Teknik Mesin Fakultas Teknologi Industri \\ Universitas Surakarta \\ Email: joyowi@yahoo.co.id
}

\begin{abstract}
ABSTRAK
Tujuan penelitian ini adalah untuk menyelidiki pengaruh temperatur tuang terhadap ketangguhan impak dan struktur mikro hasil pengecoran paduan aluminium dengan menggunakan cetakan pasir. Bahan penelitian ini adalah paduan alumunium dari scrap aluminium, kemudian dilebur dan dituang ke dalam cetakan dengan variasi temperatur tuang dari $660{ }^{\circ} \mathrm{C}, 700{ }^{\circ} \mathrm{C}$ dan $740{ }^{\circ} \mathrm{C}$. Pengujian impak dilakukan untuk mengetahui ketangguhan impak pada hasil coran dengan menggunakan alat uji impak Charpy (ASTM E 23-02a). Foto struktur mikro dilakukan dengan menggunakan mikroskop optik Nikon seri 661103. Hasil penelitian menunjukkan bahwa variasi temperatur tuang pada saat pengecoran berpengaruh terhadap nilai ketangguhan impak dan struktur mikro hasil coran. Dari tiga variasi temperatur tuang yang dilakukan, semakin tinggi temperatur tuang maka nilai ketangguhan impaknya juga semakin meningkat. Struktur mikro yang terbentuk dari logam paduan aluminium coran secara umum memiliki bentuk struktur mikro berupa struktur dendrite.
\end{abstract}

Kata kunci: aluminium, ketangguhan impak, temperatur tuang, struktur mikro.

\section{ABSTRACT}

The purpose of this study was to investigate the influence of temperature castings to impact toughness and micro-structure of aluminum alloy casting by using sand molds. This research material is an alloy of aluminum from scrap aluminum, then melted and poured into molds to cast a temperature variation of $660{ }^{\circ} \mathrm{C}, 700{ }^{\circ} \mathrm{C}$ and $740{ }^{\circ} \mathrm{C}$. The impact test was conducted to determine the impact toughness on the casting results by using a Charpy impact test (ASTM E 23-02a). Photo microstructure done using an optical microscope Nikon series 661103. Results showed that the temperature variation during the foundry castings affect the value of the impact toughness and microstructure results castings. Of the three variations of castings temperature are made, the higher the temperature castings, the value of impact toughness also increased. The microstructure formed from aluminum alloy metal castings generally have a form of micro-structure in the form of dendrite structure.

Keywords: aluminum, impact toughness, casting temperature, microstructure.

\section{PENDAHULUAN}

Pengecoran (casting) adalah suatu proses penuangan materi cair seperti logam atau plastik yang dimasukkan ke dalam cetakan, kemudian dibiarkan membeku di dalam cetakan tersebut, dan kemudian dikeluarkan atau di pecah-pecah untuk dijadikan komponen mesin. Pengecoran digunakan untuk membuat bagian mesin dengan bentuk yang kompleks [1]. 
Temperatur tuang adalah salah satu unsur penting yang harus diperhatikan dalam memproduksi produk pengecoran yang berkualitas tinggi, karena faktor ini sangat berpengaruh terhadap kualitas coran yang meliputi mikrostruktur dan sifat mekanis sehingga didapatkan hasil coran yang mempunyai sifat fisik yang baik.

Temperatur tuang merupakan salah satu variabel dari sekian banyak variabel yang terdapat pada proses pengecoran. Variabel ini penting karena jika temperatur tuang terlalu rendah maka rongga cetakan tidak akan terisi penuh dimana logam cair akan membeku terlebih dahulu pada saluran masuk, dan jika temperatur tuang terlalu tinggi maka hal ini akan mengakibatkan penyusutan dan kehilangan akan keakuratan dimensi coran.

Pengecoran dengan cetakan pasir (sand casting) merupakan metode yang banyak digunakan pada industri pengecoran Aluminium. Selain membutuhkan biaya yang cukup relatif sedikit juga dapat membuat desain yang bentuknya agak rumit, Pengecoran cetakan pasir merupakan proses produksi yang diawali dengan menuangkan logam cair ke dalam sistem saluran dan selanjutnya logam cair akan mengisi seluruh rongga cetakan. Sistem saluran cetakan pasir merupakan bagian yang sangat penting dalam pembuatan produk cetakan pasir. Hal ini dikarenakan sistem saluran merupakan jalan masuk logam cair ke dalam rongga cetak pada cetakan pasir. Sistem saluran pada pengecoran cetakan pasir terdiri dari pouring basin, sprue, runner, gate, dan riser [1].

Menurut [2], kekerasan paduan AlSi 7,79 \% hasil coran dengan teknik HPDC menurun dengan meningkatnya temperatur tuang, sedangkan struktur mikro yang berupa fasa silikon berubah dari serpihan menjadi globular dan silikon primer kecil menjadi silikon primer besar. Perubahan ini terjadi karena temperatur tuang yang tinggi menyebabkan bertambahnya waktu pembekuan dan daerah tumbuh fasa silikon sehingga pemisahan terjadi secara sempurna. Temperatur tuang mempengaruhi pembentukan struktur mikro yang berpengaruh terhadap nilai kekerasan, peningkatan temperatur tuang akan mengurangi nilai kekerasan dengan terbentuknya silikon primer.

Hasil pemeriksaan mikrografi pengecoran dengan menggunakan cawan tuang offset basin dan offset stepped basin mengalami perbedaan yang sangat signifikan jika dibanding dengan pengecoran tanpa menggunakan cawan tuang. Hasil penelitian menunjukkan bahwa pengecoran menggunakan cawan tuang offset basin maupun offset stepped basin dapat menghasilkan coran dengan cacat porositas lebih kecil dibandingkan tanpa menggunakan cawan tuang [3].

Variasi suhu tuang dan suhu cetakan akan mempengaruhi karakteristik dari benda hasil coran. Kekerasan secara umum menurun dengan meningkatnya suhu tuang dan suhu dies. Suhu tuang maksimal adalah $700{ }^{\circ} \mathrm{C}$ dan suhu cetakan $150{ }^{\circ} \mathrm{C}$ menghasilkan nilai kekerasan sebesar 97.86 VHN [4].

Semua parameter casting memiliki pengaruh yang nyata pada tegangan sisa. Tegangan sisa menurun dengan penurunan superheat, suhu dan kekerasan cetakan. Residual stress dapat ditingkatkan dengan menambahkan pengubah eutektik dan dengan perubahan desain pengecoran. Begitu juga bahwa struktur mikro dan sifat mekanik dipengaruhi secara signifikan oleh parameter tersebut [5].

Penambahan partikel SiC menyebabkan peningkatan kekuatan tarik, kekerasan, ketangguhan, umur kelelahan. Ini menunjukkan, jenis proses fabrikasi dan persentase penguat adalah faktor utama yang mempengaruhi sifat mekanik. Pengamatan menunjukkan bahwa ketika persentase penguat meningkat, pada elektromagnetik stir casting, maka diperoleh sifat mekanik terbaik [6].

Penelitian [7], mengemukakan bahwa dalam pengecoran aluminium, pengecoran ulang akan menurunkan kekuatan tarik dan kekerasan aluminium cor. Dengan penurunan sebagai berikut : pengecoran ulang I terhadap pengecoran ulang II kekuatan tarik turun 3.9\% dan kekerasannya turun 5.1\% dan setelah dilakukan pengecoran ulang III kekuatan tarik turun sekitar $8.9 \%$ dan kekerasannya turun sekitar $27 \%$.

Pengecoran ulang aluminium menghasilkan produk dengan tingkat porositas 3,3\% sampai 5,9\%. Penambahan TiB sebanyak $0,5 \%$ ke ADC3 berpengaruh pada penurunan butir hingga $50 \%$, peningkatan kekerasan hingga 23\%, peningkatan kekuatan tarik hingga $11 \%$ serta penurunan keuletan hingga $20 \%$ [8].

Menurut [9], pelapisan pola mengurangi permeabilitas gas, porositas, dan kekasaran permukaan, serta dengan melakukan pemvakuman pada saat pengecoran akan meningkatkan pemindahan gas dan memiliki efek yang jelas pada penurunan porositas. Dengan berkurangnya porositas dan kekasaran permukaan ini mengakibatkan sifat mekanisnya semakin meningkat.

Penelitian yang dilakukan [10], dengan bahan expanded polystyrene (EPS) untuk pembuatan pola yang dilapisi material pelapis rekraktori Zircon $\left(\mathrm{ZrO}_{2}\right)$ dan bahan pengikat Colloidal Silica $\left(\mathrm{O}_{2} \mathrm{Si}\right)$, menggunakan metode lost foam casting dengan ketebalan material pelapis yang diterapkan pada pola EPS yakni 0-1300 mikron. Hasil penelitian menunujukkan bahwa rata-rata akurasi ukuran untuk masing tebal lapisan pola 0 (tanpa pelapisan), 200, 500 dan 1300 mikron berturut-turut adalah -0,05, 0,04, -0,07, dan 0 ,13. Tebal lapisan 200 mikron memberikan nilai akurasi ukuran terbaik dari ketiga variasi ketebalan lapisan pola. Tebal lapisan 0 (tanpa pelapisan), 500 dan 1300 mikron akan mengakibatkan penurunan akurasi ukuran. Pola yang tidak dilapisi memiliki sifat mekanis yang lebih rendah. 
Pengecoran dengan cara melakukan pelapisan pada pola lost foam menggunakan colloidal silica dengan variasi $40 \%, 45 \%, 50 \%$ dan 55\% telah dilakukan oleh [11]. Hasil penelitian menunjukkan bahwa variasi kandungan colloidal silica terhadap ketangguhan impak secara umum mengakibatkan penurunan ketangguhan seiring dengan penambahan prosentase colloidal silica pada pola loas foam.

Penelitian tentang pengaruh temperatur tuang terhadap porositas dan sifat mekanis pada pengecoran die casting dilakukan oleh [12], menyatakan bahwa peningkatan nilai porositas disebabkan karena makin rendah temperatur tuang. Spesimen dengan temperatur penuangan $700{ }^{\circ} \mathrm{C}$ mempunyai porositas sebesar $11,8 \%$ dan semakin mengecil pada spesimen dengan temperatur penuangan $800{ }^{\circ} \mathrm{C}$ dengan porositas sebesar $11,3 \%$. Seiring dengan berkurangnya porositas maka sifat mekanisnya semakin baik.

Tujuan penelitaian ini adalah untuk menyelidiki pengaruh temperatur tuang terhadap ketangguhan impak dan struktur mikro hasil pengecoran paduan aluminium dengan menggunakan cetakan pasir.

\section{METODOLOGI PENELITIAN}

\subsection{Alat dan Bahan}

Bahan yang digunakan dalam penelitian ini berupa paduan aluminium dari sekrap aluminium dengan komposisi kimia seperti terlihat pada Gambar 1. Cetakan yang digunakan adalah cetakan pasir. Dapur peleburan dan perlengkapannya serta pyrometer sebagai pengukur temperatur.

\begin{tabular}{lcccccccccccccccccc}
\hline Unsur & $\mathrm{Al}$ & $\mathrm{Si}$ & $\mathrm{Fe}$ & $\mathrm{Cu}$ & $\mathrm{Mn}$ & $\mathrm{Mg}$ & $\mathrm{Cr}$ & $\mathrm{Ni}$ & $\mathrm{Zn}$ & $\mathrm{Sn}$ & $\mathrm{Ti}$ & $\mathrm{Pb}$ & $\mathrm{Be}$ & $\mathrm{Ca}$ & $\mathrm{Sr}$ & $\mathrm{V}$ & $\mathrm{Zr}$ \\
\hline Komposisi (\%wt) & Balance & 7,98 & 1,9 & 0,126 & 0,114 & $<0,0500$ & $<0,0150$ & 0,0526 & 4,09 & 0,0504 & 0,0440 & $<0,0300$ & 0,0001 & 0,0028 & $<0,0005$ & $<0,0100$ & 0,0210 \\
\hline
\end{tabular}

\section{Gambar 1. Komposisi Kimia}

\subsection{Proses Pengecoran}

Sebelum proses pengecoran dimulai dibuat pola coran terlebih dahulu seperti terlihat pada Gambar 2, serta pembuatan cetakan pasir. Penuangan logam cair ke dalam cetakan dilakukan pada variasi temperatur tuang $660^{\circ} \mathrm{C}, 700^{\circ} \mathrm{C}$ dan $740^{\circ} \mathrm{C}$.

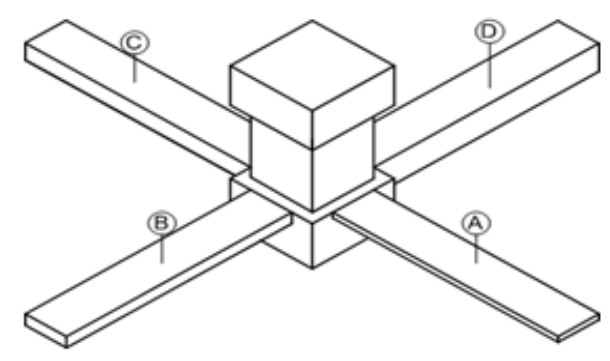

Gambar 2. Pola Coran

Keterangan gambar :

Lebar pola A, B, C dan D sama $10 \mathrm{~mm}$

Panjang pola A, B, C dan D sama $145 \mathrm{~mm}$

Tebal pola A : $4 \mathrm{~mm}, \mathrm{~B}: 6 \mathrm{~mm}, \mathrm{C}: 8 \mathrm{~mm}, \mathrm{D}: 10 \mathrm{~mm}$

\subsection{Pengujian}

Pengujian impak dilakukan untuk mengetahui ketangguhan impak pada hasil coran dengan menggunakan alat uji impak Charpy (ASTM E 23-02a). Struktur mikro dengan mengambil langsung dari permukaan bagian diameter dalam. Foto struktur mikro dilakukan dengan menggunakan mikroskop optik Nikon seri 661103. 


\section{HASIL DAN PEMBAHASAN}

\subsection{Hasil Pengujian Impak}

Pengujian ketangguhan impak hasil coran paduan aluminium pada variasi temperatur tuang $660{ }^{\circ} \mathrm{C}$, $700{ }^{\circ} \mathrm{C}$ dan $740^{\circ} \mathrm{C}$ dilakukan dengan menggunakan mesin uji impak charpy. Besarnya energi serap dan nilai ketangguhan impak dari hasil uji impak seperti terlihat pada Gambar 3 dan Gambar 4 dibawah ini.

Gambar 3 dan Gambar 4, menunjukkan bahwa pada temperatur tuang $660{ }^{\circ} \mathrm{C}$ energi serap yang dihasilkan paling rendah yaitu sebesar 1,93 Joule dengan harga impak 0,022 Joule $/ \mathrm{mm}^{2}$ karena laju pendinginannya paling cepat sehingga bahan menjadi getas. Pada temperatur tuang $740{ }^{\circ} \mathrm{C}$ energi serap yang dihasilkan paling tinggi yaitu 2,34 Joule dengan harga impak 0,034 Joule/ $\mathrm{mm}^{2}$ karena laju pendinginannya paling lambat sehingga bahan menjadi ulet. Hasil ini menunjukkan bahwa dari tiga variasi temperatur tuang yang dilakukan adalah semakin tinggi temperatur tuang pada saat pengecoran maka ketangguhan hasil coran akan semakin meningkat. Sejalan dengan penelitian yang dilakukan [2], dan [4], yaitu peningkatan temperatur tuang akan menurunkan kekerasan hasil coran dan meningkatkan ketangguhannya.

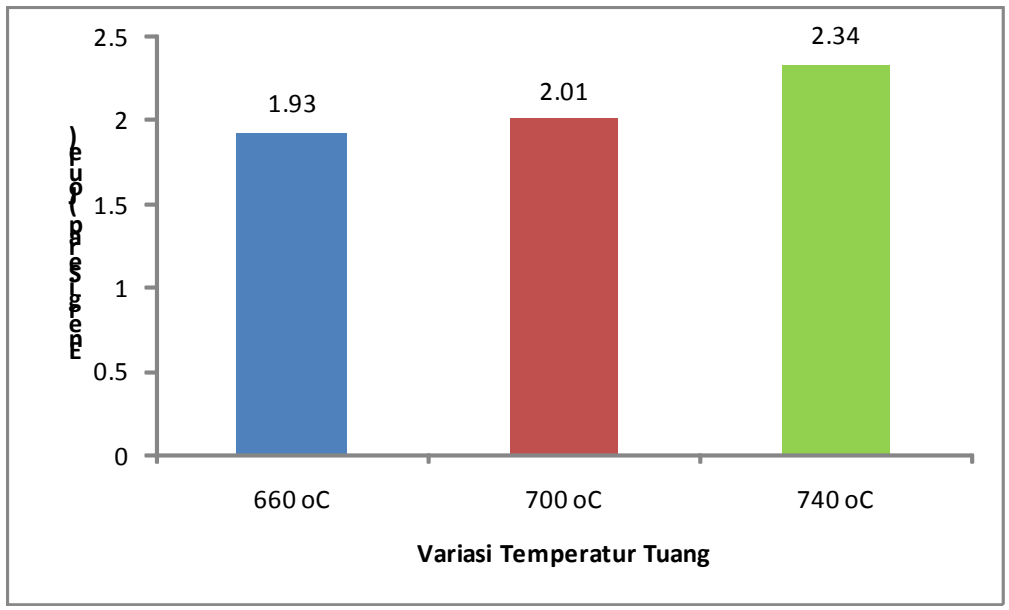

Gambar 3. Energi Serap Coran Paduan Aluminium Pada Berbagai Variasi Temperatur Tuang

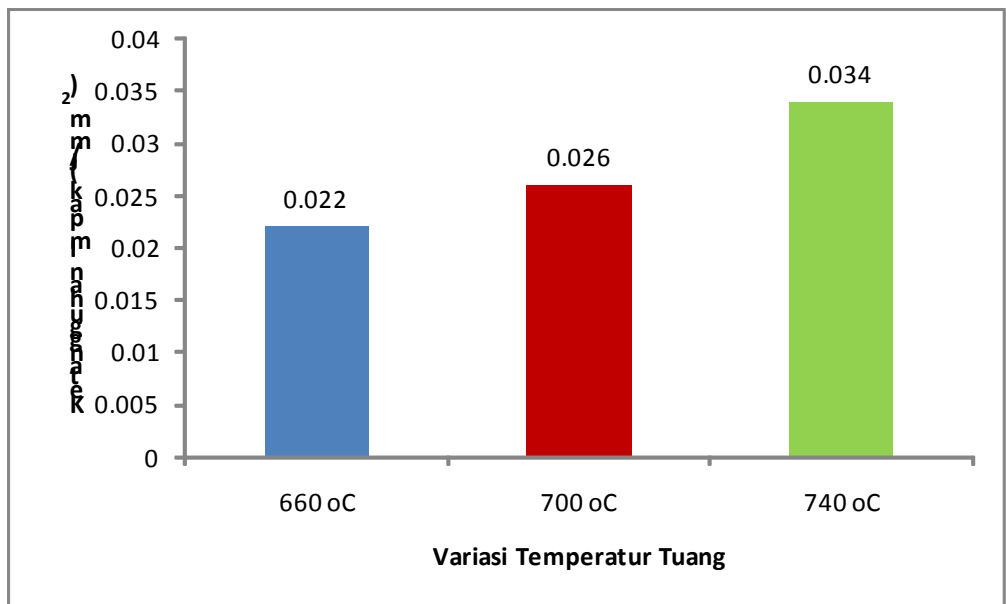

Gambar 4. Ketangguhan Impak Paduan Aluminium Pada Berbagai Variasi Temperatur Tuang

\subsection{Pengamatan Struktur Mikro}

Pengamatan struktur mikro dilakukan untuk melihat apakah terjadi perbedaan struktur mikro pada hasil coran dengan variasi temperatur tuang pada saat pengecoran. Pengamatan struktur mikro dilakukan pada ketiga spesimen variasi temperatur tuang. Pembesaran gambar sampai $100 \mathrm{X}$ dan hasil foto struktur mikro dapat dilihat pada Gambar 5. 

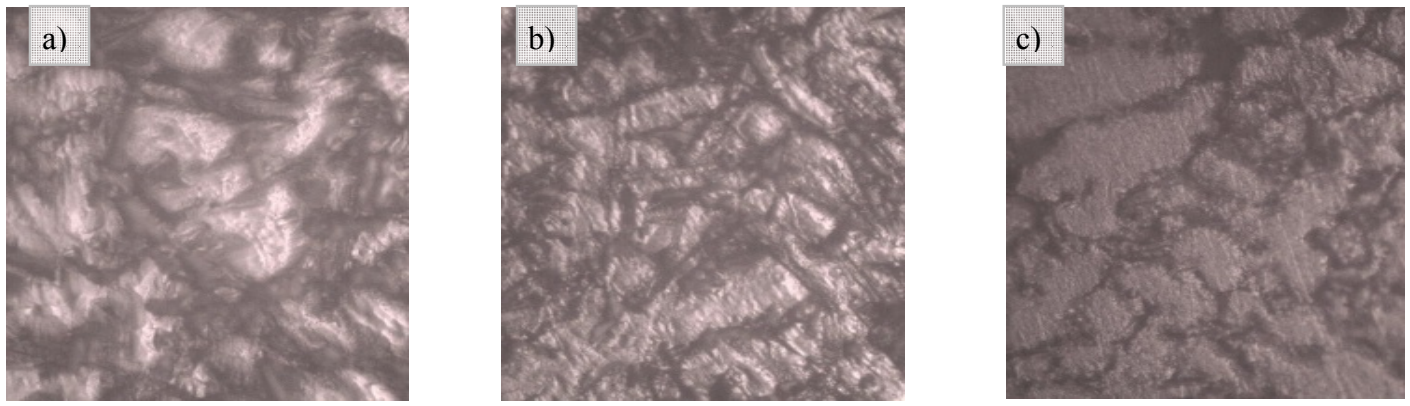

Gambar 5. Struktur Mikro Paduan Aluminium Pada Variasi Temperatur Tuang: a) $660{ }^{\circ} \mathrm{C}$, b) 700 ${ }^{\circ} \mathrm{C}$ dan c) $740{ }^{\circ} \mathrm{C}$

Hasil foto mikro logam coran menunjukkan adanya perbedaan. Secara keseluruhan struktur dari logam coran memiliki bentuk struktur mikro berupa struktur dendrite yang menjadi ciri khas dari struktur mikro dari logam paduan Al-Si. Pada variasi temperatur tuang $660{ }^{\circ} \mathrm{C}$ bentuk struktur mikronya berupa dendrite yang terbetuk belum begitu jelas dan berukuran besar pendek serta tidak teratur. Ini mengakibatkan pada waktu diuji impak menghasilkan nilai ketangguhan yang rendah, sedangkan pada variasi temperatur tuang $700{ }^{\circ} \mathrm{C}$, struktur dendrite khas dari struktur mikro coran paduan Al-Si semakin jelas dengan lengan-lengan yang panjang dan rapat yang memiliki ketangguhan yang lebih tinggi. Selanjutnya pada variasi temperatur tuang $740{ }^{\circ} \mathrm{C}$, struktur dendrite sangat jelas dengan ukuran yang lebih besar dan panjang dibanding dengan temperatur tuang sebelumnya. Struktur ini memiliki sifat yang ulet, ini terbukti pada hasil uji impak menghasilkan ketangguhan yang paling tinggi.

Hasil penelitian ini sejalan dengan [2], [3], [4], [5], [6], [7], [8], [9], [10], [11], dan [12], bahwa semua parameter pengecoran sangat berpengaruh terhadap sifat mekanik dan struktur mikro hasil pengecoran.

\section{KESIMPULAN} berikut :

Berdasarkan hasil penelitian dan pembahasan di atas maka dapat diambil kesimpulan sebagai

1) Variasi temperatur tuang pada saat pengecoran berpengaruh terhadap nilai ketangguhan impak dan struktur mikro hasil coran.

2) Dari tiga variasi temperatur tuang yang dilakukan, semakin tinggi temperatur tuang maka nilai ketangguhan impaknya juga semakin meningkat.

3) Struktur mikro yang terbentuk dari logam paduan aluminium coran secara umum memiliki bentuk struktur mikro berupa struktur dendrite.

\section{DAFTAR PUSTAKA}

[1] Surdia,T., dan Chijiwa,K., (2000). Teknik Pengecoran Logam, Cetakan Ke-8, PT. Pradnya Paramita, Jakarta.

[2] Drihandono, S., Eko Budiyanto, 2016. "Pengaruh Temperatur Tuang, Temperatur Cetakan, dan Tekanan Pada Pengecoran Bertekanan (High Pressure Die Casting/HPDC) Terhadap Kekerasan dan Struktur Mikro Aluminium Paduan Silikon (Al-Si 7,79 \%)". Jurusan Teknik Mesin, Fakultas Teknik, Universitas Muhammadiyah Metro, Lampung.

[3] Sugeng, S., dan Taufiq, H., 2010. "Pengaruh Model Saluran Tuang Pada Cetakan Pasir Terhadap Hasil Cor Logam". Prosiding Seminar Nasional Sains dan Teknologi 2010, Fakultas Teknik Universitas Wahid Hasyim Semarang, D.80 - D.85.

[4] Budi, H., dan Suyitno, 2008. "Pengaruh Temperatur Tuang Dan Temperatur Cetakan Pada High Pressure Die Casting (HPDC) Berbentuk Piston Paduan Aluminiumsilikon”. Prosiding Seminar Nasional Aplikasi Sains dan Teknologi 2008 - IST AKPRIND Yogyakarta, 86-90.

[5] Mohsen, S.S., and Sten, J., 2009. "The Effects Of Casting Parameters On Residual Stresses And Microstructure Variations Of An Al- Si Cast Alloy”. International Centre for Diffraction Data 2009 ISSN 1097-0002, $553-560$.

[6] Shashi, P.D., et.al., 2014. "Microstructure and Mechanical Properties of A356/SiC Composites Fabricated by Electromagnetic Stir Casting”. Procedia Materials Science 6. 1524 - 1532. 
[7] Helmi, P., dan Mulyonorejo, 2010. "Pengaruh Pengecoran Ulang Terhadap Kekuatan Tarik dan Kekerasan Pada Aluminium Cor Dengan Cetakan Pasir”. Prosiding Seminar Nasional Unimus, 2010, ISBN: 978.979.704.883.9, 273 - 277.

[8] Suyanto, Ratna, D.P., dan Riyanto W., 2016. "ADC3 Yang Dibuat Dengan Peleburan Ulang Aluminium Bekas Sebagai Bahan Propeler Kapal Kayu” Jurnal Simetris, Vol. 7 No. 2 November 2016, ISSN: 2252-4983, $761-768$.

[9] Guler Kerem. A., Kisasoz, A, and Karaaslan Ahmet., 2014. "Effects of Pattern Coating and Vacuum Assistance on Porosity of Aluminium Lost Foam Castings". Russian Journal of Non-Ferrous Metals, Vol. 55, No. 5, pp. 424-428.

[10] Sutiyoko, 2011. "Metode Pengecoran Lost Foam Menjawab Tantangan Dunia Industri Pengecoran Logam”. Jurnal Foundry Politeknik Manufaktur Ceper, Vol.1, pp. 21-29.

[11] Wijoyo dan Ari Fakhrudin, 2016. "Kajian Ketangguhan Impak Paduan Al-12,3Si Hasil Pengecoran Lost Foam Dengan Variasi Lapisan Colloidal Silica”. Prosiding SNTIF 3 2016, Fakultas Teknik UMK, Kudus.

[12] Bayuseno, A. P., Chamdani, A. N. 2011. "ADC 12 Sebagai Material Sepatu Rem Menggunakan Pengecoran High Pressure Die Casting Dengan Varisai Temperatur Penuangan”. Teknik Mesin, Universitas Diponegoro, Semarang.

[13] ASTM E 23-02a., 2003. Standart Test Methods for Notched Bar Impact Testing of Metallic Materials 